\title{
Role of Membranes in Bile Formation
}

\author{
COMPARISON OF THE COMPOSITION OF BILE AND A LIVER BILE-CANALICULAR \\ PLASMA-MEMBRANE SUBFRACTION
}

\author{
By W. HOWARD EVANS, TIBOR KREMMER* and JANETTA G. CULVENOR \\ National Institute for Medical Research, Mill Hill, London NW7 1AA, U.K.
}

(Received 5 September 1975)

\begin{abstract}
1. Enzymes, proteins, glycoproteins and lipids of rodent bile were compared with those of a plasma-membrane subfraction originating from the hepatocyte bile-canalicular membrane. 2. Three bile-canalicular glycoprotein enzyme activities were detected in bile. Comparison of the $\mathrm{pH}$ optimum and immunoinhibition properties of membrane and bile 5 '-nucleotidase activity indicated that they were the same enzyme. Correspondence between membrane and bile alkaline phosphodiesterases also suggested that they were the same enzymes. Activities of $\mathbf{M g}^{\mathbf{2 +}}$-stimulated adenosine triphosphatase, a lipid-dependent intrinsic membrane protein, and galactosyltransferase, a Golgi membrane marker, were not detected in bile. 3 . Rodent bile contained 15 polypeptide bands that differed radically from those of bile-canalicular membranes. Bands that may correspond in molecular weight to liver plasma-membrane glycoproteins were present at low staining intensities in bile. A major protein of apparent molecular weight 49500 was present, and albumin was detected by immunodiffusion. 4 . The lipid composition of bile and bile-canalicular membrane also differed. Phosphatidylcholine accounted for $82 \%$ of rat bile phospholipids, and only trace amounts of phosphatidylinositol, phosphatidylserine and sphingomyelin were present. 5. The results indicate that in healthy animals, the bile-canalicular membrane is refractory to the action of bile acids during the secretory process. The presence of only small amounts of bile-canalicular membrane components, especially glycoprotein enzymes located at the outer face of the membrane, suggests that these are released from the membrane by bile acids after secretion of bile into the canalicular spaces.
\end{abstract}

Despite intensive characterization of the major bile components in health and disease, little is known about the mechanism of formation of bile by hepatocytes, and its release across the bile canalicular plasma membrane into the canaliculi that unite to form the bile ductules (Hofmann \& Small, 1967; Small, 1970; Coleman, 1973). The major components of mammalian bile are the bile salts, phospholipids, cholesterol, bilirubin and electrolytes and although these have received detailed study, relatively little attention has been given to proteins and glycoproteins that are present in bile in low amounts. Bile salts and pigments are synthesized on the hepatocyte smooth-endoplasmic-reticular membranes (Mendelsohn et al., 1966; Schmid, 1972), but the immediate origin of bile lipids and proteins is not known. One possibility, suggested by Small (1970), is that the membranesolubilizing properties of bile salts (e.g. see Helenius \& Simons, 1975), may account for the presence in bile of lipids and proteins by virtue of their

\footnotetext{
* Present address: Research Institute of Oncopathology,
} Department of Biochemistry, Budapest XII, Hungary. action in solubilizing the canalicular membrane during bile secretion. This possibility is now examined experimentally by comparing directly the composition of bile and a plasma membrane subfraction shown to originate from this small specialized area of the hepatocyte surface. The bile canalicular plasmamembrane subfraction contained characteristically high specific activities of a range of hydrolytic enzymes (Wisher \& Evans, 1975) in agreement with histochemical studies (e.g. see Wachstein \& Meisel, 1957; Essner et al., 1958; Sierakowska et al., 1963). In addition, some of these enzymes were shown to be ectoenzymes, positioned at the outer boundary of the plasma membrane (Trams \& Lauter, 1974; De Pierre \& Karnovsky, 1974; Gurd \& Evans, 1974; Evans, 1974). The present work explores inter-relationships between bile canalicular membrane components and bile by comparing their enzyme, phospholipid and protein compositions. The results indicate that, in healthy animals, minor amounts of membrane components, predominantly glycoprotein enzymes, located at the outer aspect of the plasma membrane, are found in bile, thus indicating that they are re- 
moved into the canaliculi during or probably after bile secretion.

\section{Methods}

\section{Preparation of bile canalicular membranes}

Plasma membranes, sedimented in a low-speed $(10000 \mathrm{~g}$-min) pellet from liver homogenates prepared from 12 Sprague-Dawley male rats $(200-250 \mathrm{~g})$ or 75 Parke's white mice, were separated from nuclei and mitochondria by rate-zonal centrifugation through a sucrose gradient in an MSE AXII zonal rotor (Evans, 1970). The 'light' and 'heavy' plasmamembrane constituent subfractions were separated by sucrose-density-gradient centrifugation (Evans, 1970) and the 'light' subfraction, now identified as deriving from the bile-canalicular face of the hepatocyte surface (Wisher \& Evans, 1975), was used in the current studies. Liver blood-sinusoidal plasma membranes were isolated from a microsomal fraction (Wisher \& Evans, 1975).

\section{Collection of bile}

The bile ducts of male Sprague-Dawley rats (200$250 \mathrm{~g}$ ) were cannulated under ether anaesthesia, and bile was collected for periods up to $2 \mathrm{~h}$. Enzyme activities were determined on fresh bile collected within the first $20 \mathrm{~min}$. In rat, the contribution to bile of the bile ductule cells is minimal (Forker et al., 1967), and the bile is approximately ten times more dilute than mouse gall-bladder bile. Therefore for protein and phospholipid analysis, rat bile was concentrated by Diaflow filtration by using XM50 filters (Amicon Corp., High Wycombe, Bucks., U.K.). Approx. $200 \mu \mathrm{l}$ of bile was obtained with a syringe from the gall bladders of between 20 and 60 mice (Parke's or CBA strain). Serum was prepared from blood obtained by cardiac puncture from the same groups of mice. Bile was stored in small amounts at $-20^{\circ} \mathrm{C}$.

\section{Enzyme activity determinations}

Enzyme activities were determined as previously described (Wisher \& Evans, 1975). Protein was determined by the method of Lowry et al. (1951), with bovine serum albumin as standard. Before protein assay, bile protein was first precipitated with $5 \%(w / v)$ trichloroacetic acid and washed once with ethanol, ethanol/ether $(1: 1, \mathrm{v} / \mathrm{v})$ and ether.

\section{Polyacrylamide-gel electrophoresis}

Plasma membranes or bile samples (approx. $100 \mu \mathrm{g}$ of protein) were heated at $90^{\circ} \mathrm{C}$ for $5 \mathrm{~min}$ in $1 \%$ sodium dodecyl sulphate, $4 \mathrm{M}$-urea, $1 \%$ mercaptoethanol and electrophoresed for $16 \mathrm{~h}$ at $30 \mathrm{~mA}$ in flat sheets of $8.5 \%(\mathrm{w} / \mathrm{v})$ polyacrylamide, $\mathrm{pH} 8.9$, equilibrated in $0.05 \mathrm{M}$-Tris/0.4M-glycine buffer, pH 8.3, containing $0.1 \%$ sodium dodecyl sulphate (Evans et al., 1973a).

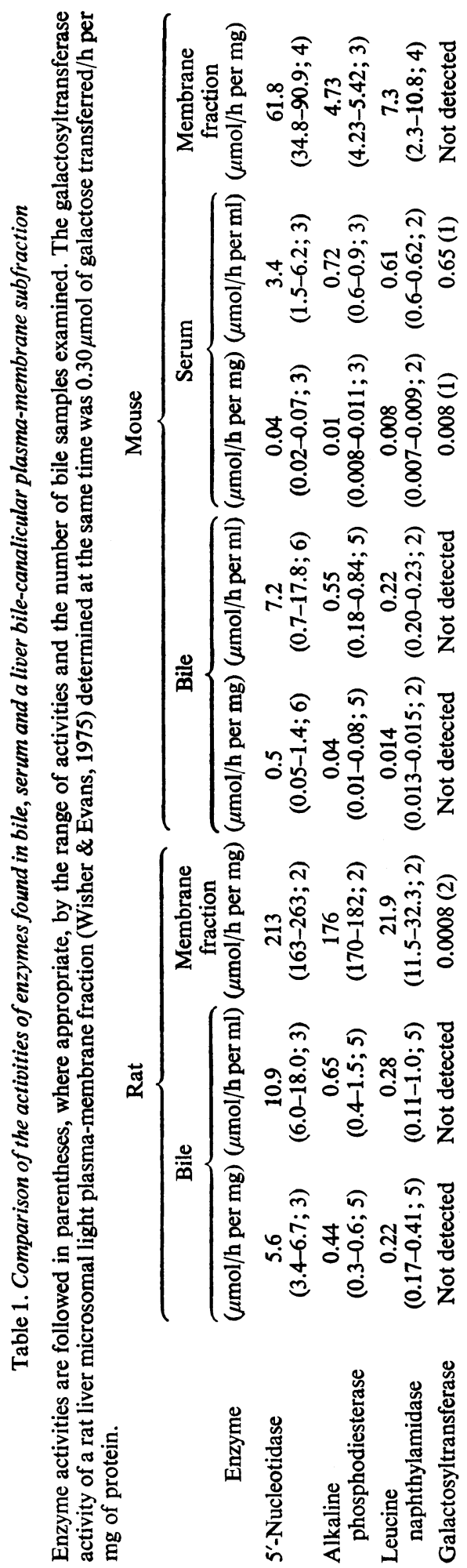


Reoviral polypeptides, rat serum albumin and $\alpha_{1}$ acid glycoprotein [Sigma (London) Chemical Co., Kingston-upon-Thames, Surrey, U.K.] were used to calibrate the gels according to molecular weight (Wisher \& Evans, 1975). Polypeptide bands, stained with Coomassie Blue, and glycoprotein bands, identified by the Schiff-periodate method, were traced by densitometry (Evans \& Gurd, 1973).

\section{Lipid analyses}

Lipids were extracted from membranes or bile as described by Folch et al. (1957); in the latter case, $0.1 \mathrm{M}-\mathrm{NH}_{3}$ was included in the upper phase to remove bile acids. Lipid extracts, concentrated by rotary evaporation, were separated by t.l.c. on $20 \mathrm{~cm} \times 20 \mathrm{~cm}$ silica-gel plates (Merck, Darmstadt, West Germany), which were developed with two solvents in succession: (a) chloroform/methanol/acetic acid/water $(60: 35: 2: 2$, by vol.) for $10 \mathrm{~cm}$, followed, after airdrying, by (b) light petroleum (b.p. $40-60^{\circ} \mathrm{C}$ )/diethyl ether/acetic acid (85:15:2, by vol.) for $5 \mathrm{~cm}$. Developed plates were sprayed with $5 \%(w / v)$ phosphomolybdic acid in $\mathrm{HClO}_{4}(10 \%$, w/v)/ethanol $(1: 1, \mathrm{v} / \mathrm{v})$. Colour development occurred after heating at $100^{\circ} \mathrm{C}$ for exactly $10 \mathrm{~min}$. The position of lipid bands was checked by running the appropriate standards. Plates were scanned by using a Joyce-Loebl densitometer, model E12, mark 3b. The amounts of the phospholipids were measured by cutting out and weighing the peak areas on the scanning paper. It was shown by direct photodensitometric scanning that the intensity of the phospholipid spots was proportional to the amount of various phospholipids present in the fractions (Christiensen-Lou et al., 1965; Christiensen-Lou \& Clausen, 1967; Neskovic, 1967; Blond et al., 1971).

\section{Immunochemical analyses}

Immunodiffusion was carried out in $1 \%$ agar (Oxoid, London SE1 9HF, U.K.) dissolved in $0.05 \mathrm{M}$-sodium barbital buffer, pH8.5, containing $1 \%$ sodium deoxycholate (Ouchterlony, 1953). Antisera were raised in rabbits to mouse and rat albumin [Sigma (London) Ltd.] and mouse liver plasma membranes, as described previously (Gurd et al., 1972).

\section{Results}

Enzymic relationships between bile and a bile-canalicular plasma-membrane subfraction

To assess the extent of release into bile of hepatic enzymes, attention was confined to three categories of membrane-bound enzymes. Three plasma-membrane enzymes found at highest activities at the bilecanalicular face of the hepatocyte (Essner et al., 1958; Wisher \& Evans, 1975) were measured in bile, serum and a bile-canalicular plasma-membrane subfraction (Table 1). $5^{\prime}$-Nucleotidase, alkaline phosphodiesterase and leucine naphthylamidase were found to be present in bile and also in serum at similar activities. Similar values for rat bile were reported by Holdsworth \& Coleman (1975). Despite the low protein content of rat and mouse bile, the specific activities of these enzymes were low in comparison with those of the bile-canalicular membranes. The results thus suggest that the loss of these enzymes from the membranes into bile is limited. In comparing the enzyme activities of bile and serum, due regard should also be given to the rates of hepatic blood flow and bile secretion, the decreased surface area of the bile-canalicular face compared with the blood sinu-

Table 2. 5'-Nucleotidase and alkaline phosphodiesterase activities of mouse bile, a bile-canalicular plasma-membrane fraction and the enzymes purified from plasma membranes as a function of $\mathrm{pH}$

Values for the purified 5'-nucleotidase are quoted from Evans \& Gurd (1973) and alkaline phosphodiesterase from Evans et al. (1973b).

Activity ( $\%$ of maximal)

pH

(a) 5'-Nucleotidase

6.5

7.6

8.5

(b) Alkaline phosphodiesterase

6.5

7.5

8.9

9.8

10.5
Enzyme purified from plasma membranes

53

100

8

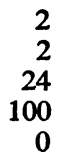

65

100

60

14

13

68

100

21
Plasma membranes

10

Vol. 154 
soidal (Oda et al., 1974), and the variable contribution of non-hepatic cells to serum enzyme activities. Steps were taken to demonstrate functional identity between membrane-bound and bile activities, especially with $5^{\prime}$-nucleotidase, since Itoh et al. (1968) and Fritzson \& Smith (1971) have shown in liver homogenates a cytoplasmic 5'-nucleotidase with maximal activity at pH6.5. Close correspondence between the enzyme activities of bile, membranes and purified 5 -nucleotidase as a function of $\mathrm{pH}$ was found (Table 2). Further correspondence between bile and membrane 5 '-nucleotidase activity was indicated by comparing the effect on enzyme activities of a rabbit anti(mouse plasma membrane) antiserum shown previously to inhibit membrane-bound and purified enzyme, but having no effect on other membrane enzymes and insulin binding (Gurd \& Evans, 1974). In summary, immune serum inhibited bile, serum and membrane $5^{\prime}$-nucleotidase activity by 100,98 and $88 \%$ respectively, although having no effect on alkaline phosphatase and phosphodiesterase activities of both bile and canalicular membranes. Table 2 also indicates that mouse bile and canalicular-membrane phosphodiesterase activities had similar $\mathrm{pH}$-activity profiles, suggesting that the membrane and bile activities are due to the same enzyme.

In the second category, ATPase* activity was examined, since it is believed to be a lipid-dependent integral (intrinsic) membrane protein (Noguchi \& Freed, 1971; Wheeler \& Whittam, 1970). No $\mathrm{Mg}^{2+}$ activated activity could be detected in rat or mouse bile. Since deoxycholic acid was shown to dissociate membrane proteins from lipids (Philippot, 1970), the absence from bile of ATPase activity could be due to the removal of lipids and/or to protein denaturation caused by the bile acids. However, although preincubation of bile-canalicular membranes with $0.5 \%$ deoxycholate completely abolished enzyme activity, preincubation of the membranes with various concentrations of rat bile for $5 \mathrm{~min}$ before measuring enzyme activity for $10 \mathrm{~min}$ in the presence of twofolddiluted rat bile lowered membrane ATPase specific activity by only $5 \%$. It was also shown by Simon \& Arias (1973) that addition of taurocholate (1-5 mM) or taurochenodeoxycholate (0.1-1 mM) stimulated slightly the activity of $\mathbf{M g}^{2+}$-activated ATPase of a rat liver plasma-membrane fraction. It was therefore concluded that the lack of ATPase activity in bile indicated extremely low amounts of enzyme rather than the inhibition or denaturation of the enzyme by the bile salts.

In the third category, galactosyltransferase was selected as an example of an intracellular membranebound enzyme located in the Golgi apparatus and in secretory vesicles that appear to move exclusively to the blood-sinusoidal surface membrane (Biava, 1964).

\footnotetext{
* Abbreviation: ATPase, adenosine triphosphatase.
}

Galactosyltransferase activity was measured in the blood-sinusoidal plasma-membrane subfraction and low activities were detected in the bile-canalicular subfraction. However, although present in serum, no galactosyltransferase activity was detected in bile (Table 1). It is considered unlikely that galactosyltransferase is present but inactive in bile, because hexosyltransferases are, in general, not inhibited by low concentrations of detergents, including deoxycholate (Mookerjea \& Yung, 1975).

\section{Comparison of proteins and glycoproteins of bile and membranes}

Polyacrylamide-gel electrophoresis indicated major differences between bile-canalicular proteins and bile proteins. Indeed, few, if any, of the bands corresponded (Fig. 1). Bile collected from rats at various time-intervals after biliary cannulation was also examined to test whether prolonged ether anaesthesia weakened the interhepatocytic junctions (Goodenough \& Revel, 1970), thus allowing mixing of blood and bile. Plate 1 shows that from $15 \mathrm{~min}$ to $2 \mathrm{~h}$, the protein composition of rat bile remained basically unchanged and the overall polypeptide profile was similar to that of mouse gall-bladder bile (Fig. 1).

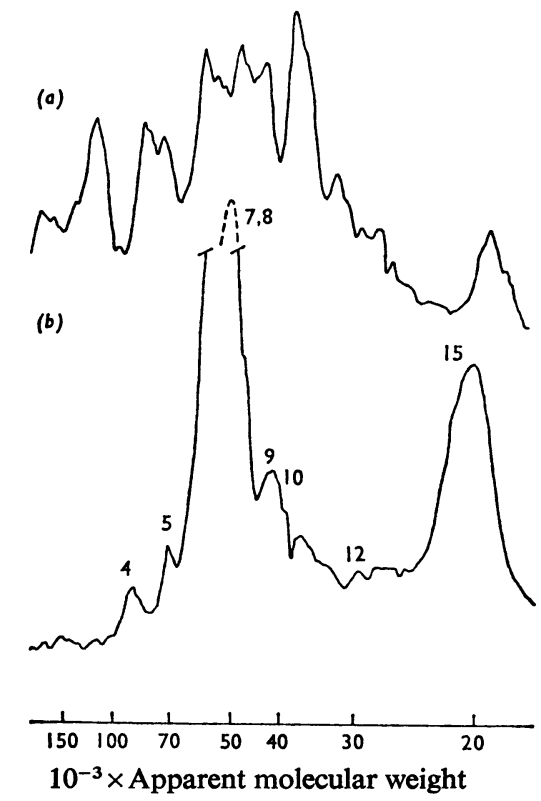

Fig. 1. Polyacrylamide-gel-electrophoretic separation of polypeptides of (a) mouse liver plasma-membrane light subfraction (Evans, 1970) and (b) pooled mouse gall-bladder bile

Electrophoresis was carried out as described in the Methods section and the numbered peaks correspond to the polypeptides of rat bile in Plate 1. 


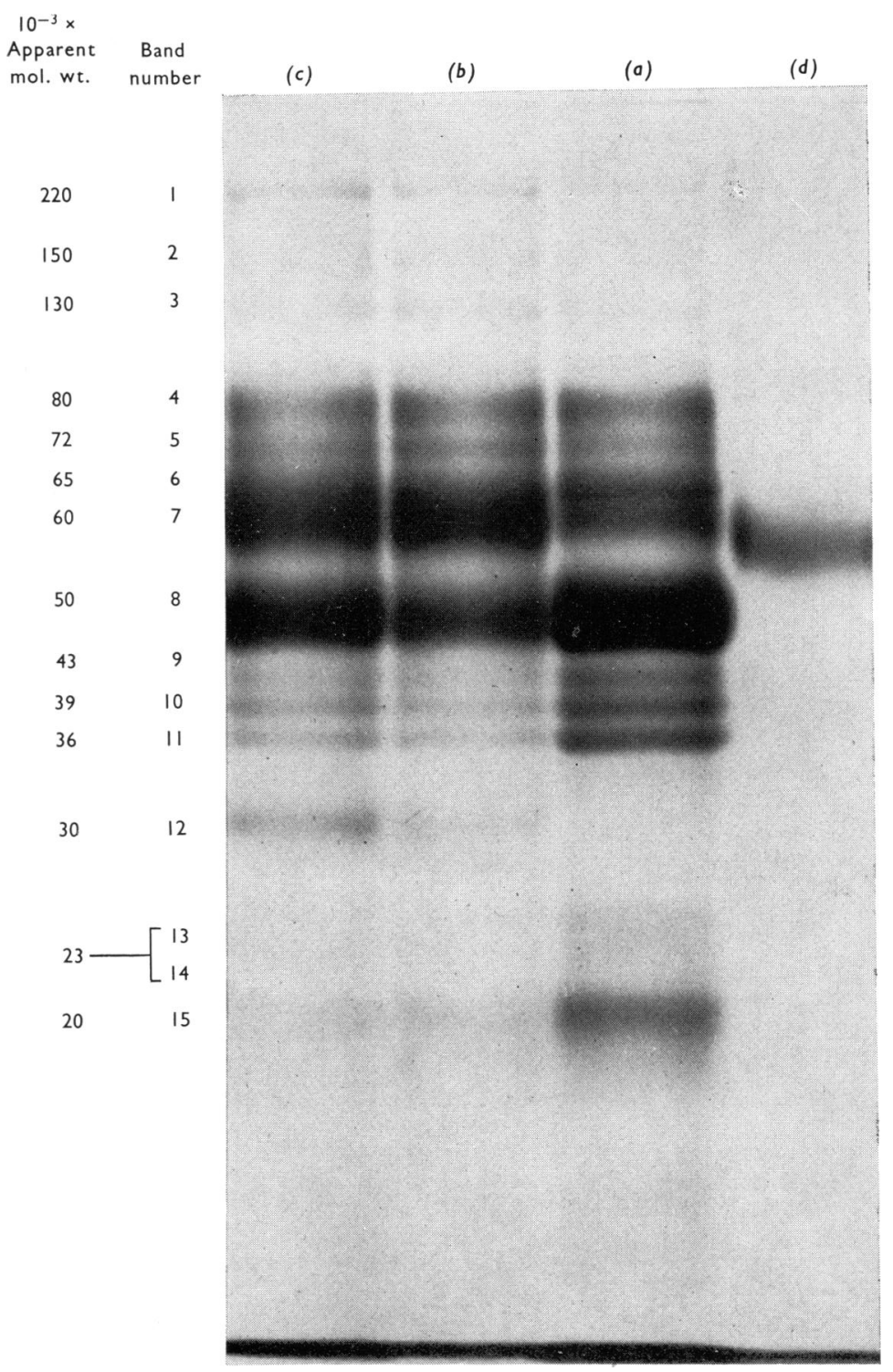

\section{EXPLANATION OF PLATE I}

Polyacrylamide-gel-electrophoretic separation of rat bile collected (a) 15-30 min, (b) 30-60 min and (c) 60-90 min after commencement of cannulation under ether anaesthesia; $(d)$ rat serum albumin

Fifteen bands were identified, and the apparent molecular weight of each polypeptide is given. For further details, see the Methods section. 
When stained for glycoproteins, approximately eight rat bile glycoproteins were detected; none of these co-electrophoresed with $\alpha_{1}$ acid glycoprotein (Fig. 2), a major glycoprotein secreted by liver that was shown not to migrate anomalously under these conditions (Glossman \& Neville, 1971).

Briefly, attempts were made to determine the origin of the major bile proteins. Although there are many reports of serum proteins being present in bile (see Hofmann \& Small, 1967) no bands corresponded to serum albumin (Plate 1). However, immunodiffusion of mouse or rat bile against their corresponding antialbumin antisera showed cross-reactivity (not shown). Albumin in bile thus runs anomalously in polyacrylamide gels equilibrated in sodium dodecyl sulphate, as was previously shown by using starch-gel electrophoresis (Rawson, 1962). Although bile glycoproteins were suggested to be associated with mucus (Bouchier \& Freston, 1968), there is some

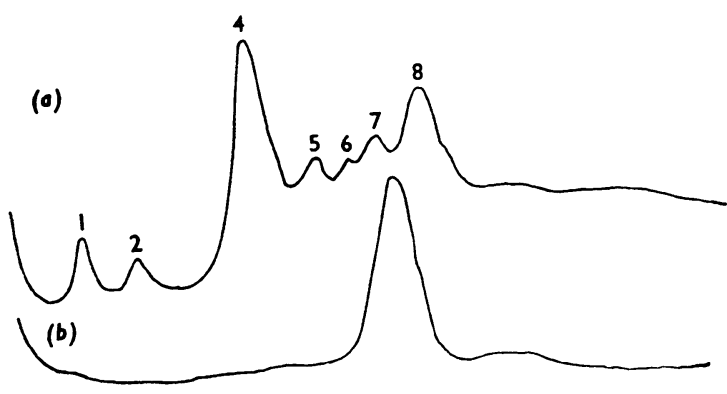

Fig. 2. Polyacrylamide-gel-electrophoretic separation of the glycoproteins of $(a)$ rat bile and $(b) \alpha_{1}$ acid glycoprotein

The numbered peaks correspond to those of bile collected from 15 to $30 \mathrm{~min}$ in Plate 1. Electrophoresis and gel staining were carried out as described in the Methods section. correspondence between their apparent molecular weight on polyacrylamide gels, for example, bands 1 and 2 (Fig. 2), and those determined for purified plasma-membrane glycoprotein enzymes. The question of the origin of other proteins in bile and whether they are specific to bile therefore still remains.

\section{Comparison of lipid composition of bile and membranes}

Lipids extracted from bile-canalicular membranes and bile were compared by t.l.c. The lipid composition of bile-canalicular membranes determined by an approximate method was generally similar to that of unfractionated plasma membranes (Ray et al., 1969) and differed from that of bile which, in agreement with previous reports (Nakayama \& Blomstrand, 1961 ; Spitzer et al., 1964), contained large amounts of phosphatidylcholine (Table 3) and cholesterol. However, trace amounts of phospholipids that were present in higher amounts in bile-canalicular membranes, relative to other hepatic membranes, were also found in bile, namely sphingomyelin, phosphatidylinositol and phosphatidylserine. The organizational disposition of liver plasma-membrane phospholipids in relation to the phospholipid bilayer is not known (Emmelot \& van Hoeven, 1975).

\section{Discussion}

The present results, by comparing the composition of a bile-canalicular membrane fraction and bile from rats and mice, indicate that little dissolution of membrane components into bile occurs in healthy animals. The major protein and phospholipid components of membrane and bile differed greatly, and therefore it appears unlikely that the bile-canalicular plasma membrane contributes substantially to bile composition. However, the results indicate that in addition to phosphatidylcholine, trace amounts of other phospholipids present in characteristically

Table 3. Comparison of the phospholipid compositions of rat bile and a bile-canalicular membrane fraction

Lipid extracts of membranes or bile were separated by t.l.c., stained and the relative phospholipid compositions were determined as described in the Methods section.

\section{Phospholipid}

Lysophosphatidylcholine

Sphingomyelin

Phosphatidylcholine

Phosphatidylethanolamine

Phosphatidylinositol

Phosphatidylserine

Minor phospholipids

Composition ( $\%$ of total phospholipids)

$\overbrace{\text { Bile Bile-canalicular }}^{\text {membranes }} \begin{gathered}\text { Total plasma } \\ \text { membranes* }\end{gathered}$

2.9

14.0

36.1

24.5

7.5

15.1
3.3

17.7

34.9

18.5

7.3

9.0

9.2

* Values quoted from Ray et al. (1969). 
higher amounts in liver plasma membranes, e.g. sphingomyelin and phosphatidylinositol, were detected, thus suggesting a slight loss of membrane phospholipids into bile. Similarly, although polyacrylamide-gel electrophoresis indicated major differences between bile and membrane polypeptide profiles, the enzyme results show that membrane glycoprotein enzyme activities were present in bile. Minor bands corresponding to the molecular-weight positions of these enzymes were also detected by polyacrylamidegel electrophoresis. These enzyme activities were similar to those measured in serum, thus contrasting with organic anions (bile acids, pigments, porphyrins) that are present in bile at concentrations very much greater than their simultaneous concentration in serum. Interestingly, one class of membrane-bound enzymes detected in bile corresponds to a specific category of bile-canalicular membrane enzymes. 5'Nucleotidase, alkaline phosphodiesterase and leucine naphthylamidase are glycoproteins (Evans \& Gurd, 1973; Evans et al., 1973b; Wacker, 1974) located at the outer surface of the hepatocyte plasma membrane (Trams \& Lauter, 1974; Gurd \& Evans, 1974; Evans, 1974; Farquhar et al., 1974). Therefore, although the bile-canalicular plasma membrane appears to be largely refractory to the action of bile salts during their transport across the membrane, it is instructive to note that one category of enzyme activities present in bile probably derives from membrane ectoenzymes favourably located for direct removal into the canaliculi. The solubilizing action of detergents, including bile salts, on membranes occurs optimally at high concentrations, and it is likely that bile acids pass across the bile-canalicular membrane at concentrations well below those inducing the formation of mixed detergent-membrane lipid micelles that are a prerequisite for membrane solubilization (Helenius $\&$ Simons, 1975). The refractoriness of the canalicular plasma membrane to bile salts is thus explained, and the presence in bile of low activities of membrane ectoenzymes probably results from the action on the outer surface of the membrane of bile present in the canaliculi. During certain clinical conditions, e.g. obstructive jaundice, increased activities of 5'nucleotidase, alkaline phosphatase and phosphodiesterase and leucine naphthylamidase are found in serum (Pope \& Cooperband, 1966), and it may be hypothesized that this is a consequence of an accumulation of bile in the canaliculi leading to the extraction into bile of larger amounts of the above enzymes, principally from the outer surface of the bilecanalicular membrane but also into serum from the contiguous and sinusoidal areas as the bile permeates the interhepatocytic space.

The absence of galactosyltransferase from bile agrees with the low activity of this enzyme at the bilecanalicular membrane. Galactosyltransferase is a predominantly Golgi-located membrane-bound en- zyme (Bergeron et al., 1973a) functioning in glycosylation reactions, and the higher activities detected in the blood-sinusoidal plasma-membrane fraction was suggested to be due largely to contamination of this fraction by Golgi components (Wisher \& Evans, 1975). 5'-Nucleotidase was also detected on Golgi membranes (Farquhar et al., 1974) and it is likely that it is initially inserted into the hepatocyte surface membrane at the blood-sinusoidal face (Bergeron et al., 1973b), whence it may move laterally in the plane of the membrane to the bile-canalicular membrane surface domain. This biosynthetic scheme argues that the enzymes present on both surface domains of the hepatocyte are identical, and thus direct loss of 5'-nucleotidase into serum from the blood sinusoidal surface can also occur as shown for sugar transferase enzymes (Kim et al., 1972). Alterations in cholestasis to bile composition, and to the morphology of hepatocytes (Desmet, 1972), are thus open to biochemical studies at the membrane level that should clarify further the role of components present at the various domains of the hepatocyte surface, especially the bile-canalicular membrane, in bile formation.

T. K. thanks The Royal Society and The Hungarian Academy of Sciences for a fellowship. We thank Dr. H. Gordon for help with bile-duct cannulations.

\section{References}

Bergeron, J. J. M., Ehrenreich, P., Siekevitz, P. \& Palade, G. E. (1973a) J. Cell Biol. 59, 73-88

Bergeron, J. J. M., Evans, W. H. \& Geschwind, I. (1973b) J. Cell Biol. 59, 771-776

Biava, C. G. (1964) Lab. Invest. 13, 840-864

Blond, J. P., Lemarchal, P. \& Le Breton, E. (1971) Biochimie 53, 1221-1224

Bouchier, I. A. D. \& Freston, J. W. (1968) Lancet i, 340344

Christiensen-Lou, H. O. \& Clausen, J. (1967) Clin. Chim. Acta 18, 465-475

Christiensen-Lou, H. O., Clausen, J. \& Bierring, F. (1965) J. Neurochem. 12, 619-627

Coleman, R. (1973) in Form and Function of Phospholipids (Ansell, G. B., Dawson, R. M. C. \& Hawthorne, J. N., eds.), pp. 345-375, Elsevier, Amsterdam

De Pierre, J. W. \& Karnovsky, M. L. (1974) J. Biol. Chem. 249, 7111-7120

Desmet, V. J. (1972) Prog. Liver Dis. 4, 97-132

Emmelot, P. \& van Hoeven, R. P. (1975) Chem. Phys. Lipids 14, 236-246

Essner, E., Novikoff, A. B. \& Masek, B. (1958) J. Biophys. Biochem. Cytol. 4, 711-716

Evans, W. H. (1970) Biochem. J. 116, 833-842

Evans, W. H. (1974) Nature (London) 250, 391-394

Evans, W. H. \& Gurd, J. W. (1973) Biochem. J. 133, 189199

Evans, W. H., Bergeron, J. J. M. \& Geschwind, I. I. (1973a) FEBS Lett. 34, 259-262 
Evans, W. H., Hood, D. A. \& Gurd, J. W.(1973b) Biochem. J. 135, 819-826

Farquhar, M., Bergeron, J. J. M. \& Palade, G. E. (1974) J. Cell Biol. 60, 8-25

Folch, J., Lees, M. \& Sloane-Stanley, G. H. (1957) J. Biol. Chem. 226, 497-509

Forker, E. L., Hicklin, T. \& Sornson, H. (1967) Proc. Soc. Exp. Biol. Med. 126, 115-119

Fritzson, P. \& Smith, I. (1971) Biochim. Biophys. Acta 235, 128-141

Glossman, H. \& Neville, D. M. (1971) J. Biol. Chem. 246, 6339-6346

Goodenough, D. A. \& Revel, J. P. (1970) J. Cell Biol. 45, 272-290

Gurd, J. W. \& Evans, W. H. (1974) Arch. Biochem. Biophys. 164, 305-311

Gurd, J. W., Evans, W. H. \& Perkins, H. R. (1972) Biochem. J. 130, 271-280

Helenius, A. \& Simons, K. (1975) Biochim. Biophys. Acta 415, 29-80

Hofmann, A. F. \& Small, D. M. (1967) Annu. Rev. Med. $18,333-376$

Holdsworth, G. \& Coleman, R. (1975) Biochim. Biophys. Acta 389, 47-50

Itoh, R., Mitsui, A. \& Tsushima, K. (1968) J. Biochem. (Tokyo) 63, 165-169

Kim, Y. S., Perdomo, J., Whitehead, J. S. \& Curtis, K. J. (1972) J. Clin. Invest. 51, 2033-2039

Lowry, O. H., Rosebrough, N. J., Farr, A. L. \& Randall, R. J. (1951) J. Biol. Chem. 193, 265-275

Mendelsohn, D., Mendelsohn, L. \& Staple, E. (1966) Biochemistry 5, 3194-3198

Mookerjea, S. \& Yung, J. W. M. (1975) Arch. Biochem. Biophys. 166, 223-236
Nakayama, F. \& Blomstrand, R. (1961) Acta Chem. Scand. 15, 1595-1603

Neskovic, N. M. (1967) J. Chromatogr. 27, 488-490

Noguchi, T. \& Freed, S. (1971) Nature (London) 230, 148-150

Oda, M., Price, Y. M., Fisher, M. M. \& Phillips, M. J. (1974) Lab. Invest. 31, 314-323

Ouchterlony, O. (1953) Acta Pathol. Microbiol. Scand. 32, 231-240

Philippot, J. (1970) Biochim. Biophys. Acta 225, 201-213

Pope, C. E. \& Cooperband, S. R. (1966) Gastroenterology 50, 631-636

Rawson, A. J. (1962) Clin. Chem. 8, 310-317

Ray, T. K., Skipski, V. P., Barclay, M., Essner, E. \& Archibald, F. M. (1969) J. Biol. Chem. 244, 5528-5536

Schmid, R. (1972) N. Engl. J. Med. 287, 703-709

Sierakowska, H., Szemplinska, H. \& Shugar, D. (1963) Acta Biochim. Pol. 10, 399-411

Simon, F. R. \& Arias, I. M. (1973) J. Clin. Invest. 52, 765-775

Small, D. M. (1970) Adv. Intern. Med. 16, 243-264

Spitzer, H. L., Kyriakides, E. S. \& Baline, J. A. (1964) Nature (London) 204, 288

Trams, E. G. \& Lauter, C. J. (1974) Biochim. Biophys. Acta 345, 180-197

Wachstein, M. \& Meisel, E. (1957) Am. J. Clin. Pathol. 27, 13-23

Wacker, H. (1974) Biochim. Biophys. Acta 334, 417-423

Wheeler, K. P. \& Whittam, R. (1970) Nature (London) 225, 449-450

Wisher, M. H. \& Evans, W. H. (1975) Biochem. J. 146, 375-388 